International Journal of Music in Early Childhood, accepted 1/5/20

DOI: https://doi.org/10.1386/igmec_00010_1

\title{
Moving towards music: Viewing early years musical engagement through the lenses of movement, interaction, motivation, agency, identity, and context
}

Alexandra Lamont, Keele University

\begin{abstract}
This article provides a broad overview of the theoretical approaches underpinning our understanding of early musical development, and considers how this sets the foundation for later development across the lifespan. Through a review of research evidence and theory, I argue for the importance of interaction in thinking about musical development: movement is at the heart of theories of development, interaction and synchrony form the foundation for music learning, and motivation, agency and identity shape patterns of early engagement with music. The importance of setting these activities in context is also emphasised: for parents, teachers and researchers to fully understand young children's musical experiences it is vital to consider the cultural contexts and histories of the musical materials, the listener, and the situation, as well as how these interact.
\end{abstract}

Keywords: movement, interaction, motivation, agency, identity, context

\section{Introduction}

Musical engagement occurs well before birth. Our earliest response to music and sound is clearly physical, and in utero motor responses to sound have been demonstrated by about 20-25 weeks (Chelli and Chanoufi, 2008) and heart rate changes by 33 weeks (Kisilevsky, Hains, Jacquet, Granier-Deferre, and Lecanuet, 2004). Repeated exposure to complex auditory stimuli prenatally leads a foetus to demonstrate a familiarity response, whether that be movements or changes in heart rate (usually deceleration) (DeCasper, Lecanuet, Maugeais, Granier-Deferre and Busnel, 1994).

Research has explored the potential for memories to be formed before birth and recognised after birth, which Parncutt termed 'transnatal memory' (2016). For instance, Partanen et al. (2013) created a melodic version of the popular children's song Twinkle Twinkle Little Star. Mothers were asked to play the recording five times a week for the last trimester of pregnancy, making an average of 171 repeated exposures. Immediately after birth and at the age of 4 months, infants were played both the original and a slightly modified version of the melody which did not alter significant anchoring notes. Those infants who had been played the music before birth showed a stronger brain response as measured by eventrelated potentials to both the original and altered versions than those who had never heard the melody before.

This demonstrates that infant preferences for music start being shaped before birth and that this comes from repeated exposure to particular sounds. Thus preferences are found for the mother's voice compared with other female voices (DeCasper and Fifer, 1980) and for intra-uterine versions of the mother's voice over airborne versions (Spence and Freeman, 1996). Either casual or deliberate repeated pre-natal exposure to more complex 
forms of music, such as Peter and the Wolf (Feijoo, 1981) or the television programme Neighbours' theme music (Hepper, 1991), also result in post-natal recognition.

Early experiences with sound and music before birth prime us for early receptiveness to both speech and music in infancy (Costa-Giomi and Ilari 2014), and music forms a central part of parent-infant interactions and caregiving rituals in every culture around the world (Custodero, 2006; Ilari et al., 2011; Malloch and Trevarthen, 2009; Young, 2008). Singing provides the foundation for musical experience in infancy (Trehub, 2019). It is well established that many young children have a considerable amount of music exposure. Around two-thirds of parents of infants in the first year of life report singing to and playing music for their infants (Custodero et al., 2002), and musical engagement also includes infant music classes (Perkins and Fancourt, 2018). Young et al. (2006) noted that, in addition to singing, recorded music also featured highly in experiences of children under two.

I draw on evidence from a wide range of sources about young children's experiences with music to make six key theoretical points which are important for all those working in early years music to consider. This is not intended to be a comprehensive review of research in early years, nor of theories of development (see, e.g. Hargreaves and Lamont [2017]; Young and Ilari [2019]), but to provide some provocation for early years researchers and practitioners around these six key theoretical points.

\section{Beginning with movement}

Considering theoretical approaches to understanding very early development (Hargreaves and Lamont, 2017), all the 'grand' developmental theories begin with a motoric element. For instance, Piaget's (1953) stage theory starts with the sensori-motor stage, covering the period from birth to 2 years, and arguing that the only representations an infant can have of the world are based on input from the senses and demonstrated through movements. Similarly, Bruner (1966) proposed the enactive phase as the first mode of understanding. Other theoretical approaches to development also embody or include movement or action, such as cultural-historical activity theory (Engeström, 1987).

We can observe responses to music that involve action very early in development, as noted earlier, but how might infants begin to co-ordinate their response to organised sound? Winkler et al. (2009) found that newborns were able to detect the beat in drum patterns while asleep. Using ERP, infants' responses to predicted beats were strong, while they showed surprise in response to omitted downbeats after a beat had been established. Experience of music can influence this early response to motion. Cirelli et al. (2016) found that infants of 7 and 15 months could synchronize to beat patterns more clearly if either they, or their parents, had more musical experience. Even short-term active engagement can shape this motoric response. 6-month-old infants who had watched an adult drum were less likely to notice a subsequent video of an adult drumming where the audio and video were not in synchrony. However, infants who had just drummed themselves were better able to notice this lack of synchrony, suggesting that their participation in the activity supported their music learning (Gerson et al., 2015). 
Does movement indicate interest? Spontaneous movement happens in young infants and toddlers aged between 5 and 24 months more frequently with drums and music than with speech, and rhythmic co-ordination with music is positively related to displays of positive affect (Zentner and Eerola, 2010). However, the assumption that motion simply equates to interest in early infancy is incorrect. Many infants respond to music through a 'startle' response which resembles stillness, but they maintain their gaze towards sound sources which indicates interest. This ability is detectable as soon as infants can physically coordinate their own body to demonstrate independent behaviours, whether this be eye movements, sucking, or head-turning.

All of these movements have been harnessed by infant researchers in order to test discrimination, recognition, and preference with music as well as other kinds of stimuli (see Trehub, 2016). In one technique, infants are either presented with two contrasting pieces of music, sequentially, and control the amount of exposure they get to each by maintaining gaze towards the sound source. In another, they are presented with a repeating musical sequence until they have habituated and then a change is introduced, which would be correctly recognised by a change of eye gaze, sucking rate or a head turn. Thus, movement is a critical starting-point for both our theorising and our research with very young children.

\section{Interaction}

Interaction is also intrinsic to cultural-historical activity theory (Engeström, 1987), and coordinating one's actions with another is a powerful means of bonding. More recently, Molnar-Szakacs et al. (2012) have identified the building blocks of understanding to be affective motion experiences which are shared through the mirror neuron system. Simply observing motion in another person activates this mirror neuron system and strengthens the neural pathways associated with movement.

Gaining skills in synchronising is an important feature of early years development (Tomasello et al., 2005). Infants will be guided by others in many ways, and music can provide a way of facilitating synchronising skills. Cirelli et al. (2014) put 14-month-old infants in a situation where they were either bounced by an assistant in synchrony or out of synchrony with an experimenter standing opposite them: each adult was guided in their synchronising by a beat track played on headphones. Afterwards, the experimenter accidentally dropped some objects which the infants could 'help' by picking up, and more helping behaviour was observed following the in-synchrony bouncing. Cirelli et al. found the same amount of helping behaviour when the infants were bounced in synchrony but out of phase, suggesting that the underlying cause of the helping behaviour was the contingency of movement between the two adults rather than a simple mirroring of the symmetry of actions, and this study shows that motor synchrony seems to promote the very early development of altruistic behaviour.

Action and interaction is at the heart of many early years music programmes, and the plethora of early-years and infant music classes based on bouncing and other physical actions such as waving, walking in time, and dancing suggests that interaction through music carries intrinsic benefit. It also shapes the way infants respond to music. In the period between 6 and 12 months of age, infants are learning about their culture: the music and 
language which is around them shapes the way they respond to particular musical patterns, with Western infants coming to understand tonality as an organising system for music (Werker and Tees, 1984; Trehub et al., 1999). Active musical experience during that time, in the form of Suzuki-based early years music classes with movement, has been found to be more helpful in this early learning than simply listening to music (Gerry et al., 2012): infants who had 6 months of active music experience were more likely to prefer a tonal classical piece to distorted versions.

As young children become able to generate and control their own movements, more evidence is found for the importance of synchronization for non-musical outcomes. Kirschner and Tomasello (2009) found that children aged between 2.5 and 4.5 years were more accurate in their synchronising (drumming with a partner) when the drumming was presented in a social context, i.e. with another person rather than a recording or a drum machine. This supports the social underpinnings of musical experience and learning: having another person's input definitely makes a difference. This synchronisation can have other outcomes as well. Kirschner and Tomasello (2010) found prosocial effects of group music making in 4-year-olds, as the children who had engaged in joint singing and dancing for 3 minutes were more helpful and co-operative with each other than other children who had carried out a comparable non-musical activity together.

In summary, this research shows that from the starting point of movement in response to music, early years development takes the form of greater co-ordination of action with others. Increasing synchronisation ability in early childhood promotes interaction with others, and supports both musical and non-musical learning.

\section{Motivation is vital}

It is well known that perseverance with an activity requires motivation, but where might motivation for active engagement with music come from? Csikszentmihalyi's (1990) concept of flow provides some explanation for why experiences might be rewarding. Flow refers to a situation where both skill and challenge are high: there is a need for clear goals, and opportunities to gain feedback, which enable the given activity to provide opportunities for mastery, problem solving and transformation. Most of the research on motivation in development refers to expertise in performing skills and to later stages in childhood and adolescence. The key messages from that literature are that effort is necessary, with an average of 10,000 hours of practice is required to achieve an expert state in music (Sloboda et al., 1996), and that children's continued involvement in music depends on a set of individual characteristics including autonomy, resilience, achievement goals, incremental beliefs about one's own ability, and motivation (Austin, Renwick and McPherson, 2006). There is an assumed progression from extrinsic motivation in the early stages, relying on the support of others and external rewards, to intrinsic motivation later on as the learner develops a strong self concept and ability to reward themselves, sustaining the extensive practice required for success (Renwick and Reeve, 2012). So, how might this work in the early years?

Csikszentmihalyi (1993) suggested that young children are in flow almost all the time, and flow has been studied in a range of early years music settings. For instance, Custodero 
(2005) observed infants and two-year-olds in music groups in childcare settings and schoolaged children in Suzuki violin and Dalcroze classes. She coded their behaviours in terms of challenge-seeking (illustrated through self-assignment, self-correction, and gesture), challenge-monitoring (anticipation, expansion and extension) and the social context (awareness of adults and peers). She observed subtle changes in the types of behaviour seen across the age range studied: infants were aware of adults and demonstrated deliberate gestures, while anticipation was fully developed by the age of 2 . Self-assignment and extension expanded between infancy and toddlerhood and declined in school-aged children, while peer awareness and self-correction increased linearly with age.

Motivation theories as developed in relation to later child development place a strong emphasis on the role of agency. For instance, Ryan and Deci's (2000) self-determination theory sets out the contributions of autonomy, relatedness and competence as a way of understanding how intrinsic motivation develops. I move on to consider agency specifically in the next section; as with many elements of development, different concepts are often intertwined.

\section{The role of agency}

As soon as infants become able to act on the world, their own intentions and actions become important, and this can be observed in a number of contexts with music. Wiggins (2016) draws on Bandura's social cognitive theory to include three types of agency. Learner agency - learners' constructions of their own understanding within social contexts - derives from the theoretical views of Vygotsky and others that interactions with others shape and construct the child's learning within social context. Personal agency refers to the belief that the learner can engage, initiate, and intentionally influence their own life circumstances, which relates to Ryan and Deci's (2000) self-determination theory. Finally, musical agency, specifically applied to music learning, involves aspects of learner as well as of personal agency. Fostering and enabling agency and independence are at the heart of learning and development for Wiggins.

Sole (2017) has observed toddlers aged 18-36 months in what she terms 'crib song': spontaneous music-making from the baby in the pre-sleep period, as well as interviewing their parents. Drawing on rich observational data Sole has been able to chart how toddlers interact with their parents and other musical 'tools' such as toys, and how they use vocalisation to self-soothe, to reflect musical bonds between themselves and others, and to make sense of their relationships with parents. For instance, Margot (age 26 months) vocalised through a fully improvised repertoire of learned tunes like 'Skip to my Lou', 'Frere Jacques', and 'Itsy Bitsy Spider', playing with motives, humming with closed mouth around her bottle, and repeating segments in different pitch repertoires. Lorraine (30 months) shared a bedtime routine with her mother involving singing songs and being rocked on a rocking chair, and created her own independent song called 'Lorraine is my baby', providing a musical bond. Similarly, Robyn (31 months) created songs about her parents which she sang at appropriate moments, reflecting their relationships and influence on her life. These examples show how very young children take an active role in creating and using music for emotional regulation and for connecting with others. 
In a very different context, Custodero et al. (2016) studied spontaneous musical behaviours on the New York subway, using Winnicott's psychoanalytic framework to interpret musical behaviours as sources of comfort and engagement. Over three weekends, observers coded 69 examples of children's music making in public, from infancy to age 10, which was coded for its musical qualities, sources, and contexts. Custodero et al. observed that children's music-making was partly influenced by adult interactions, showing a continuation of the importance of others in early musical development. However, the majority of the musical episodes were coded as 'solitary', where children drew on resources in the environment such as engine noises or other people singing or talking. Singing was the most common form of musical activity, reflecting $81 \%$ of episodes, and these results continue to underline the importance of movement, as $48 \%$ of episodes involved some kind of motion.

Looking at young children's own choices of music in everyday settings, Lamont (2008) captured experience-sampling data over a week with parents and caregivers of 3.5 year old children, asking them whether music is being played, what the context is and how the child reacts. Music was heard either during or in the two hour period preceding the call in $81 \%$ of cases ( $37 \%$ on the call, $43 \%$ just preceding), in contrast to a total of $44 \%$ of episodes for adults (Juslin et al., 2008). Music was more likely to be heard at home than at nursery, and almost all the car journeys involved music. Children's music and pop music were the most heard styles, and surprisingly, children chose $40 \%$ of the music themselves without help and $6 \%$ in conjunction with peers or siblings. Other influencers were mothers (20\%), teachers and other caregivers (16\%), with fathers only choosing music $0.5 \%$ of the time. Children's own choice of music was mostly children's music, while parents and adults were more likely to choose pop and other styles and for background purposes.

These studies show a diversity of musical behaviours with the common thread of agency. The behaviours observed by Custodero et al. (2016) clearly illustrate musical agency outlined by Wiggins, as the young children adapt to their environment and in turn make an impression on it through musical gestures and actions. Agency is also underpinned here by choice: young children are able to select the environmental noises, musical inspiration, or appropriate pre-existing music for a given situation.

\section{Developing a musical identity}

The exercise of choice and agency in music, as in other spheres of life, leads towards developing a clear musical identity - what it means to think of oneself as a musician - which is an important factor in sustaining musical experiences. Higher autonomy, independence and responsibility in music-making are more likely to lead to sustained engagement (Green, 2001), helping develop "resilient" musicians (Creech et al., 2008). Beginning from Trevarthen and Malloch's communicative musicality (2017), musical identity starts with recognition of importance of others and relationships between people. The importance of developing a robust identity in music has been clearly demonstrated (Lamont, 2002, 2017; MacDonald et al., 2017). However, when considered across the lifespan, musical identities are diverse, multiple, and fluid.

Erikson (1982) provides a useful theoretical framework on identity, setting out eight different stages where conflicts are resolved through identity crises to reach positive 
characteristics (Table 1). The actions, interactions, and sense of agency developed through early years music making provide infants with a sense of trust about the people around them. Early childhood (ages 1.5 to 3 years) is characterised by the development of autonomy and purpose, as illustrated well by the work on emotional self-management in crib song by Sole (2017) discussed earlier. Barrett's (2016) analysis of 2-year-old Cara's music-making in a range of home settings shows how young children can explore different musical roles and trial their own musical identities as singer, composer, and performer. Barrett shows, for instance, how Cara creates songs and song fragments for everyday activities like cooking or trampolining as well as pretend rituals such as answering the phone or going to work. In this identity work, Cara uses singing to engage in story-telling which provides her with an explanation of her own actions both for herself and for others.

Table 1: Erikson's (1982) stages of identity

\begin{tabular}{|l|l|l|l|l|}
\hline Age & Years & \multicolumn{2}{|c|}{ Conflict between } & $\begin{array}{l}\text { Positive } \\
\text { characteristics }\end{array}$ \\
\hline Infancy & $0-1.5$ & Trust & Mistrust & Hope \\
\hline Early childhood & $1.5-3$ & Autonomy & Shame and doubt & Will \\
\hline Play age & 3 to 5 & Initiative & Guilt & Purpose \\
\hline School age & 5 to 12 & Industry & Inferiority & Competence \\
\hline Adolescence & 12 to 18 & Identity & Role confusion & Fidelity \\
\hline Young adulthood & 18 to 40 & Intimacy & Isolation & Love \\
\hline Adulthood & 40 to 65 & Generativity & Stagnation & Care \\
\hline Maturity & $65+$ & Integrity & Despair & Wisdom \\
\hline
\end{tabular}

Agency develops into motivation and purpose in what Erikson labelled 'play age' (preschoolers), illustrated by the agency shown by Lamont's (2008) 3.5 year olds and by the travelling toddlers in Custodero et al.'s (2016) subway study. Motivation continues through the development of competence in the school years, and this is where most of the work on developing musical identity in terms of performing has been focused, whereas developing musical identity as a listener is more associated with the adolescent phase where music preferences are used to establish friendship groups and allegiances. In terms of performance, young children begin their formal music-making with generally high levels of musical self-esteem. Primary school children are generally positively disposed towards making music and singing (Lamont, Hargreaves, Marshall and Tarrant, 2003; Lamont, Daubney and Spruce, 2012). Prior to having music lessons, 6-year-olds were found to retain their initial confidence in their ability to improve with their music lessons after they had been given an artificial situation with feedback that they had failed ( $O^{\prime}$ Neill and Sloboda, 1997). This shows the growth mindset that Dweck (2000) believed was important for success in formal education, which is an important recognition for beginning performers who have a long journey ahead of them in terms of skill development and practice. However 
at the upper end of what we might still term 'early years', around the age of 7, social comparisons become much more important and negative feedback can have significant effects on children's musical aspirations and motivations. These negative attitudes can persist across the lifespan (Lamont, 2011), and can cloud people's desire to become involved in music-making.

The research on musical identity development across the lifespan suggests that there are no straightforward routes, and that many people may struggle to identify the right kind of music-making. Research with older singers suggests that they still have a growth mindset and are prepared to engage in new activities and opportunities for learning (Lamont et al., 2018). However, pinpointing the specific musical activities that work for individuals can take considerable time. In interviews with older amateur music-makers, many varied routes were found towards the activities the adults were currently engaged in, as exemplified by this quote from Rosemary (aged 65):

"I did continue playing [the piano after childhood] purely for enjoyment. I was asked at school to learn the viola but my parents couldn't afford this. Then I devoted my time to study/work/combination work and children. I always loved music and thought that playing in a group or orchestra would be really enjoyable. My three children all had music lessons, the middle one also accordion. After my illness I felt I needed an activity purely for myself - to relax more etc - and took up the accordion which I really love playing." (Lamont, in preparation)

This quote shows the different patterns and pathways that may be necessary before someone identifies the right kind of music for them, and highlights the importance of providing many and varied opportunities from early childhood to maximise the chances that something might 'stick'.

\section{Context is vital: music, listener, and situation}

Bronfenbrenner's ecological systems theory provides a useful way of understanding what is meant by context. In the original formulation (Bronfenbrenner, 1979), microsystems refer to the immediate settings of children's lives, in their families, peer groups, and schools. The links between these form mesosystems, in which different microsystems interact with one another (events at school might influence what children do at home, for example).

Exosystems are broader social settings which exert more indirect influences on children's behaviour, such as community groups or parents' associations, and macrosystems exert the most the most indirect and abstract influences, such as government policies or social classbased institutions. Bronfenbrenner subsequently (1986) expanded the model to account for the additional dimension of time, since context is not static: the range of musical opportunities open to young children in 2020 are very different to those of the midtwentieth-century, for instance.

Considering the various contexts of the early years, family clearly provides the starting point for most musical opportunities, as illustrated in the evidence supporting pre-natal memory formation with music and the growing body of work on parent-infant interactions at home. For instance, Sole's (2017) work identifies a particular cultural niche of the crib and just 
before bedtime, whereas Addessi (2009) studied fathers bonding with their infants while changing their nappies through the use of play, vocalisation and imitation, thereby developing early synchrony. Young and llari (2012) have mapped how infants' and young children's musical engagement is a function of their engagement with the world around them, looking at how singing and playing instruments can mirror other individuals or the environment around them (e.g. television or environmental sounds), and this identification of different niches can be very useful in understanding the range of potential influences and influencers as well as the activities that music goes along with. Young and Ilari's example of Mitchell, a 3-year-old boy, imitating the sound of a garbage truck passing by and then adapting this into a creative version of 'The Wheels on The Bus' has much resonance with the identification of creative musical engagement found by Custodero et al. (2016) on the subway.

As children get older, home continues to be important (cf. Young et al., 2012), but more formal contexts also begin to play a role, such as childcare, nursery, and school. In my own work I found that school played a central role in shaping children's developing musical identities (Lamont, 2002). In response to the simple question 'do you play a musical instrument', children from primary schools where more specialist tuition was available were more likely to say no, while children from schools where extra opportunities were fewer were more likely to say yes. The children were influenced by what they experienced around them: when a third of their class went to have extra-curricular music lessons at school, this created the impression that music was not something everybody did, which seemed to lead to the more negative views held by those not engaging in this special activity.

We can identify different musical contexts according to their position on the dimensions of formal-informal and statutory-elective (Hargreaves, Marshall and North, 2003). For the early years, informal 'elective' activities would include parent/infant singing, independent singing, and music and games at home and beyond, while formal 'elective' activities include early years music classes, interactive Suzuki and Kodály music training programmes, and individual instrumental lessons. Informal 'statutory' experiences would include celebration music and ritual, while formal statutory experiences include the school environment itself and the National Curriculum. Following Bronfenbrenner's approach to consider how these contexts are themselves shaped by external forces and how they might interact with one another is an important priority for future research in the early years and music. Does it matter if the musical cultures of home and school are different, for instance? How might children use music as a bridge between unfamiliar settings, as they begin to expand their social world? What music are we introducing into different settings, and what expectations might we have of how young children will respond?

\section{Concluding remarks}

I have set out six key theoretical topics that merit reflection by all those involved in early years music making, as parents, teachers, and researchers. In keeping with the theme of the EU-MERYC conference, movement seems to be at the heart of many developmental theories and provides the foundation for much theorising about music development. We have seen how interaction and synchronisation form the fundamental building blocks of learning and development in music, and that important aspects of interpersonal relations 
such as the ability to synchronise can have benefits beyond music such as influences on prosocial behaviour. Motivation, agency and identity are three closely related concepts that all acknowledge the increasing role that children play on the world as they grow older, and the importance of self-regulation and commitment to particular activities comes to the fore across the early years period. The positive identities that are shown by many young children are to be celebrated and supported as children move into a more comparative and selfcritical phase at the end of the early years period, as we can see that positive musical identity can sustain engagement for many years to come and is a vital factor in helping children, and adults, through difficult transition periods.

Finally, context is vital. When thinking about a given musical experience it is essential to take into account the cultural positioning and history of the music itself, the listener or performer, and the situation. Whether we are looking to understand more about infants singing themselves to sleep, toddlers making up songs about experiences in the world, or children taking their first steps with instrumental tuition, these key factors need to be considered.

\section{References}

Addessi, A. R. (2009). The musical dimension of daily routines with under-four children during diaper change, bedtime and free play. Early Child Development and Care, 179(6), 747-768.

Austin, J., Renwick, J., and McPherson, G. E. (2006). Developing motivation. In G. E. McPherson (Ed.), The child as musician: A handbook of musical development (pp. 213238). Oxford: Oxford University Press.

Barrett, M. (2016). Attending to "culture in the small": A narrative analysis of the role of play, thought and music in young children's world-making. Research Studies in Music Education, 38(1), 41-54.

Bronfenbrenner, U. (1979). The ecology of human development. Cambridge, MA: Harvard University Press.

Bronfenbrenner, U. (1986) Ecology of the family as a context for human development: Research perspectives. Developmental Psychology, 22(6), 723-742.

Bruner, J. S. (1966). Toward a theory of instruction. Cambridge, MA: Belknapp Press.

Chelli, D., and Chanoufi, B. (2008). Audition foetale: Mythe ou realité ? Journal de Gynécologie Obstétrique et Biologie de la Reproduction, 37(6), 554-558.

Cirelli, L. K., Einarson, K. M., and Trainor, L. J. (2014). Interpersonal synchrony increases prosocial behavior in infants. Developmental Science, 16(6), 1003-1011.

Cirelli, L. K., Spinelli, C., Nozaradan, S., and Trainor, L. J. (2016). Measuring neural entrainment to beat and meter in infants: Effects of musical background. Frontiers in Neuroscience, 10, 29: DOI: 10.3389/fnins.2016.00229.

Costa-Giomi, E. and Ilari, B. (2014). Infants' preferential attention to sung and spoken stimuli. Journal of Research in Music Education, 62(2), 188-194.

Creech, A., Papageorgi, I., Duffy, C., Morton, F., Haddon, E., Potter, J., de Bezenac, C., Whyton, T., Himonides, E., and Welch, G. (2008). From music student to professional: the process of transition. British Journal of Music Education, 25(3), 315-331.

Csikszentmihalyi, M. (1990). Flow: The psychology of optimal experience. New York: Harper and Row. 
Csikszentmihalyi, M. (1993). The evolving self: A psychology for the third millennium. New York: Harper Collins.

Custodero, L. A. (2005). Observable indicators of flow experience: A developmental perspective on musical engagement in young children from infancy to school age. Music Education Research, 7(2), 185-209.

Custodero, L. A. (2006). Singing practices in 10 families with young children. Journal of Research in Music Education, 54(1), 37-56.

Custodero, L., Britto, P. R. and Xin, T. (2002). From Mozart to Motown, lullabies to love songs: A preliminary report on the Parents' Use of Music with Infants Survey (PUMIS). Zero to Three, 23(1), 41-46.

Custodero, L. A., Calì, C., and Diaz-Donoso, A. (2016). Music as transitional object and practice: Children's spontaneous musical behaviors in the subway. Research Studies in Music Education, 38(1), 55-74.

DeCasper, A. J., and Fifer, W. P. (1980). Of human bonding: newborns prefer their mother's voice. Science, 208(4448), 1174-1176.

DeCasper, A. J., Lecanuet, J.-P., Maugeais, R., Granier-Deferre, C., and Busnel, M.-C. (1994). Fetal reactions to recurrent maternal speech. Infant Behavior and Development, 17(2), 159-164.

Dweck, C. S. (2000). Self-theories: Their role in motivation, personality and development. Philadelphia, PA: Psychology Press.

Engeström, Y. (1987). Learning by expanding: An activity theoretical approach to developmental research. Helsinki: Orienta-Konsultit Oy.

Erikson, E. H. (1982). The life cycle completed: A review. New York: W. W. Norton and Company, Inc.

Feijoo, J. (1981). Le foetus Pierre et le loup ... ou une approche originale de l'audition prenatale humaine. In: E. Herbinet and M. C. Busnell (Eds.), L'aube des sens (pp. 192-209). Paris: Stock.

Gerry, D. W., Unrau, A. and Trainor, L. J. (2012). Active music classes in infancy enhance musical, communicative and social development. Developmental Science, 15(3), 398407.

Gerson, S. A., Schiavio, A., Timmers, R., and Hunnius, S. (2015). Active drumming experience increases infants' sensitivity to audiovisual synchrony during observed drumming actions. PLoS One, 10(6), e0130960, doi:10.1371/journal.pone.0130960.

Green, L. (2001). How popular musicians learn: A way ahead for music education. Aldershot: Ashgate.

Hargreaves, D. J., and Lamont, A. (2017). The Psychology of Musical Development. Cambridge: Cambridge University Press.

Hargreaves, D. J., Marshall, N., and North, A. C. (2003). Music education in the $21^{\text {st }}$ century: a psychological perspective. British Journal of Music Education, 20(2), 147-163.

Hepper, P. G. (1991). An examination of fetal learning before and after birth. The Irish Journal of Psychology, 12, 95-107.

Ilari, B., Moura, A., and Bourscheidt, L. (2011). Between interactions and commodities: Musical parenting of infants and toddlers in Brazil. Music Education Research, 13(1), 5167.

Juslin, P. N., Liljeström, S., Västfjäll, D., Barradas, G. and Silva, A. (2008). An experience sampling study of emotional reactions to music: listener, music, and situation. Emotion, $8(5), 668-683$. 
Kirschner, S., and Tomasello, M. (2009). Joint drumming: Social context facilitates synchronization in preschool children. Journal of Experimental Child Psychology, 102(3), 299-314.

Kirschner, S., and Tomasello, M. (2010). Joint music making promotes prosocial behavior in 4-year-old children. Evolution and Human Behavior, 31(5), 354-364.

Kisilevsky, B. S., Hains, S. M., Jacquet, A.-Y., Granier-Deferre, C., and Lecanuet, J. P. (2004). Maturation of fetal responses to music. Developmental Science, 7(5), 550-559.

Lamont, A. (2002). Musical identities and the school environment. In: R. A. R. MacDonald, D. J. Hargreaves and D. E. Miell (Eds.), Musical identities (pp. 41-59). Oxford: Oxford University Press.

Lamont, A. (2008). Young children's musical worlds: Musical engagement in three-yearolds. Journal of Early Childhood Research, 6(3), 247-261.

Lamont, A. (2011). The beat goes on: Music education, identity and lifelong learning. Music Education Research, 13(4), 369-388.

Lamont, A. (2017). Musical identity, interest, and involvement. In: R. A. R. MacDonald, D. J. Hargreaves, and D. E. Miell (Eds.), Handbook of Musical Identities (pp. 176-196). Oxford: Oxford University Press.

Lamont, A. (in preparation). Lifelong amateur engagement with music: identity and wellbeing.

Lamont, A., Daubney, A. and Spruce, G.J. (2012). Singing in primary schools: case studies of good practice in whole class vocal tuition. British Journal of Music Education, 29(2), 251-268.

Lamont, A., Hargreaves, D. J., Marshall, N. A., and Tarrant, M. (2003). Young people's music in and out of school. British Journal of Music Education, 20(3), 229-241.

Lamont, A., Murray, M., Hale, R. and Wright-Bevans, K. (2018). Singing in later life: the anatomy of a community choir. Psychology of Music, 46(3), 424-439.

MacDonald, R. A. R., Hargreaves, D. J., and Miell, D. E. (2017) (Eds.). Handbook of musical identities. Oxford: Oxford University Press.

Malloch, S., and Trevarthen, C. (2009). Communicative musicality: Exploring the basis of human companionship. Oxford: Oxford University Press.

Molnar-Szakacs, I., Green Assuied, V., and Overy, K (2012). Shared affective motion experience (SAME) and creative, interactive music therapy. In: D. J. Hargreaves, D. E Miell, and R. A. R. MacDonald. (Eds.), Musical imaginations (pp. 313-331). Oxford: Oxford University Press.

O'Neill, S. A. and Sloboda, J. A. (1997). The effects of failure on children's ability to perform a musical test. Psychology of Music, 25(1), 18-34.

Parncutt, R. (2016). Prenatal development and the phylogeny and ontogeny of musical behavior. In: S. Hallam, I. Cross, and M. Thaut (Eds.), The Oxford handbook of music psychology (2 ${ }^{\text {nd }}$ Edition, pp. 371-386). Oxford: Oxford University Press.

Partanen, E., Kujala, T., Tervaniemi, M. and Houtilainen, M. (2013). Prenatal music exposure induces long-term neural effects. PLOS One, 8(10), e78946.

Perkins, R., and Fancourt, D. (2018). Maternal engagement with music up to nine months post-birth: Findings from a cross-sectional study in England. Psychology of Music, 46(2), 238-251.

Piaget, J. (1953). The origins of intelligence in children. London: Routledge and Kegan Paul. 
Renwick, J., and Reeve, J. (2012). Supporting motivation in music education. In: G. McPherson and G. Welch (Eds.) The Oxford handbook of music education, 1 (pp. 143162). Oxford: Oxford University Press.

Ryan, R. M., and Deci, E. L. (2000). Self-determination theory and the facilitation of intrinsic motivation, social development, and well-being. American Psychologist, 55(1), 68-78.

Sloboda, J. A., Davidson J. W., Howe, M. J. A., and Moore D. M. (1996). The role of practice in the development of expert musical performance. British Journal of Psychology, 87(2), 287-309.

Sole, M. (2017). Crib song: Insights into developmental functions of toddlers' private spontaneous singing. Psychology of Music, 45(2), 172-192.

Spence, M. J., and Freeman, M. S. (1996). Newborn infants prefer the maternal low-pass filtered voice, but not the maternal whispered voice. Infant Behavior and Development, 19(2), 199-212.

Tomasello, M., Carpenter, M., Call, J., Behne T., and Moll, H. (2005). Understanding and sharing intentions: the origins of cultural cognition. Behavioral and Brain Sciences, 28(5), 675-735.

Trehub, S. E. (2016). Infant musicality. In: S. Hallam, I. Cross, and M. Thaut (Eds.), The Oxford Handbook of Music Psychology (pp. 387-398). Oxford: Oxford University Press.

Trehub, S. E. (2019). Nurturing infants with music. International Journal of Music in Early Childhood, 14(1), 9-15.

Trehub, S. E., Schellenberg, E.G., and Kamenetsky, S. B. (1999). Infants' and adults' perception of scale structure. Journal of Experimental Psychology: Human Perception and Performance, 25(4), 965-975.

Trevarthen, C., and Malloch, S. (2017). The musical self: Affections for life in a community of sound. In: R. A. R. MacDonald, D. J. Hargreaves and D. E. Miell (Eds.), Handbook of musical identities (pp. 155-175). Oxford: Oxford University Press.

Werker, J. F., and Tees, R. C. (1984). Cross-language speech perception: evidence for perceptual reorganization during the first year of life. Infant Behavior and Development, 7(1), 49-63

Wiggins, J. (2016). Musical agency. In G. E McPherson (Ed.), The child as musician: $A$ handbook of musical development (pp. 102-121). Oxford: Oxford University Press.

Winkler, I., Háden, G.P., Ladinig, O., Sziller, I., and Honing, H. (2009). Newborn infants detect the beat in music. Proceedings of the National Academy of Sciences, U.S.A., 106(7), 2468-2471. DOI: 10.1073/pnas.0809035106

Young, S. (2008). Lullaby light shows: Everyday musical experience among under twos. International Journal of Music Education, 26(1), 33-46.

Young, S., et al. (2012). MyPlace, MyMusic: An international study of musical experiences in the home among seven-year-olds. Israel Studies in Musicology Online, 10.

Young, S., and Ilari, B. (2012). Musical participation from birth to three: toward a global perspective. In: G. McPherson and G. Welch (Eds.), Oxford Handbook of Music Education Volume 1 (pp. 279-295). Oxford: Oxford University Press.

Young, S., and Ilari, B. (2019) (Eds.). Music in Early Childhood: Multi-disciplinary perspectives sand inter-disciplinary exchanges. New York: Springer.

Young, S., Street, A., and Davies, E. (2006). The Music One2One Project: final report. University of Exeter, available online at http://education.exeter.ac.uk/music-one2one/ Zentner, M. and Eerola, T. (2010). Rhythmic engagement with music in infancy. Proceedings of the New York Academy of Sciences, 106(13), 5768-5773. 